\title{
CONSERVATION OF BROADLAND
}

$\mathrm{A}^{\mathrm{N}}$ $\mathrm{N}$ adjournment debate in the House of Commons on July 12 on the Broads as a national park was initiated by Mr. J. Parker almost simultaneously with the publication of the Nature Conservancy's Report on Broadland*.

The Report was referred to both by Mr. Parker himself and Mr. B. Hazell, while in replying on the debate Mr. A. Skeffington, the Joint Parliamentary Secretary to the Ministry of Land and Natural Resources, said that the Ministry welcomed the Report as stimulating, knowledgeable and imaginative and that he was studying it with great interest. Mr. Parker re-opened the question of clearing the Broads of weeds, which ten years ago he had estimated would cost about $\mathfrak{\text { l }}$ million. He pressed for a positive policy with regard to the Broads in the interests of both holiday makers and residents in the area, and hoped that it would be possible to interest the new University of East Anglia in the problems of the area, and to encourage it to assist in research. Mr. Hazell also referred to the need for such a policy, quoting the Strategic Plan for Broadland stressed in the Nature Conservancy's Report. Mr. Skeffington agreed that it was essential for the whole future of the countryside and the future of this area to be viewed afresh in the light of a rapidly changing situation, including a considerable increase in population and a great increase in mobility. $\mathrm{He}$ said that the Minister was making a thorough and comprehensive review of all the problems associated with the countryside and admitted that this was much overdue, and that the present expenditure of $£ 43,000$ by the National Parks Commission under the Act was derisory. The review being made at present would consider not only the needs of the parks already designated but also of possible future parks, which would be areas of recreation calling for greater accessibility than required in the national parks themselves. This review was substantially completed and the Minister hoped to reach a conclusion on this shortly. Finally he admitted that the problem was urgent and that, as the Nature Conservancy's Report stated, time was not on the side of Broadland and to do nothing would be to abandon the region to erosion, conflict and decay.

The Nature Conservancy's Report follows an earlier draft, and the recommendations now included are based on discussions on this draft. The General Survey contains the factual material, which constitutes the second chapter, and this is followed by one on present trends and another giving the Conservancy's appraisal and conclusions. Recommendations are set forth in the final chapter and these call for a basic policy to conserve and enhance the Broadland environment for holidays and for outdoor recreation as well as research and education. For holidays and such outdoor recreational activities as angling, yachting, dinghy racing, nature study and canoeing, which are essential leisurely pursuits, for research and education and for agriculture, Broadland provides a unique setting. The Report directs attention to the need for some understanding of the forces shaping the environment which increase the value of Broadland for basic scientific studies and biological education. Some recreational activities, both now and in the future, could be much better met in other areas, in or near large conurbations, but the total impact of existing demands on Broadland is large, and increasing. There are unmistakable signs that without positive sound policies for the longterm planning, management and development of the region many of its special features will degenerate, and much of its charm and value will be lost. Much of it is ecologically unstable and the restorative processes of

The Nature Conservancy. Report on Broadland. Pp. 98 (27 plates). (London: The Nature Conservancy, 1965.) 178. 6d.
Nature cannot keep pace with the demands on them. Future policies must take full account of all these considerations and the Report insists on the need for a strategic plan for Broadland containing both short- and long-term features. Its detailed preparation will call for co-operative effort from many experts, and its implementation will demand full understanding at regional level and encouragement and guidance at national level. Its broad objectives must be the maintenance and enhancement of the Broadland environment; the harmonization of the activities and uses, for example, by space and time zoning; and an expansion programme involving the creation of new Broads and waterways, planned, managed and developed to meet further demands and to offer further scope for zoning. The success of the plan will require acceptance of the precept that longterm planning, management and development of the Broadland's resources of land and water and wild life must be based on research and education. The problems arising from incompatible uses are aggravated by overcrowding, which also prevents the best use being made of a given area. Accordingly, all proposals for expanding the use of Broadland must be based on an appraisal of the social and economic advantages of this use, and must be weighed against any resultant degradation of the environment. This calls for research and study to establish what the real advantages and effects of use are likely to be.

Certain steps can be taken under existing statutory powers and by negotiation, for example, in relation to pollution of the Broadland waterways from whatever source. It is recommended that appropriately constituted expert groups should be established to consider and advise on pollution, the performance of eraft intended for use on the waterways, on mooring facilities, on the requirements for caravans, house-boats and 'flat-a-floats' and on a code of behaviour. Discussions between interested parties, phased as part of the plan, should also be initiated to examine the pre-requisites for increased use of those waterways at present closed to navigation or restricted in use. The full use in Broadland of existing powers to cater for the recreational activities on water should be urgently studied by the River Authorities, and discussion should be held to explore the possibilities of extending the application of zoning, both in time and space, as a means of minimizing conflict between incompatible uses. Detailed consideration should be given to the practicability of creating new Broadland waterways since these would help to meet existing and future demands for more water space and also to distribute present and forecasted pressures more evenly and to facilitate zoning.

A supplement by certain members of the working party is appended in which the recommendations are based on the fact that at present no single authority can hope to identify all the facts or to provide solutions within its own powers. Accordingly, it is proposed that, as a matter of urgency, the Government should establish machinery to designate "National Recreational Areas", together with an agency to administer them and to provide facilities for outdoor recreation in the countryside generally, and that Broadland should be designated as one of these areas.

Some authority should be invested with financial resources and responsibility for preparing a long-term strategic plan and, pending the completion and adoption of this plan, this authority should seek to ensure the co-ordination and unity essential for the effective planning, management and development of the region. The Conservancy also recommends that as soon as possible a consortium be established of the planning, river, and navigation authorities with an independent chairman of standing, appointed by the Government. Meanwhile the 
consortium should be empowered to implement any proposals falling within the powers of the authorities constituting it; to encourage and facilitate appropriate action by other bodies; and to develop support among other bodies and the general public for the policies and measures proposed. It should maintain close working liaison between the interests concerned and create new facilities for the public enjoyment of Broadland within the strategy of the Conservancy's Report, as well as maintain constant review of trends and developments in the area and initiate action to obtain data on them. It should also detect and appraise gaps in the powers required to implement fully the agreed policies, and advise on the economic implications of these proposals.

\section{RADIOCHEMICALS}

$\mathrm{H}$ UR booklets have recently been issued by the Radio. chemical Centre, Amersham*.

The first, Selected References to Tracer Techniques, is a revised edition and contains a bibliography of selected publications useful to newcomers to tracer work. The contents consist of titles of general texts and articles dealing with the preparation of labelled compounds, tracer applications, methods of measurement and safety precautions.

Radioactive Isotope Dilution Analysis is a second edition of the booklet in which the principle of the analysis is explained and shown to be a sensitive method of determ. ination of many substances in mixtures. It is emphasized that the technique does not require expensive laboratory facilities or materials. The application of the method is illustrated by particular examples.

Problenas of radiation self-decomposition of materials are of increasing interest to users of radioactive tracer compounds, and the summary of experience gained from the storage of radioactive compounds at the Radiochemical Centre which is given in the third booklet, The Stability of Labelled Organic Compounds, should be very helpful. The information is largely empirical. Data for a number of compounds are listed. The essential factors in the investigation or observation of the decomposition from selfirradiation are the chemical character of the molecule which determines the liability to primary (external) and secondary effects; the purity, the solvents and diluents, the concentration, the specific activity, the temperature and other environmental conditions; and the type and

* The Radiochemical Centre. Selected References to Tracer Techniques. Revised edition. Pp. 12. Radioactive Isotope Dilution Analysis. Second Edition. Pp. 12. The Stability of Labelled Organic Compounds. Pp. 14 Standards of Activity. By G. R. Newbery et al. Pp. 27. (Amersham; The Radiochemical Centre, 1965.) energy of the radiation from the incorporated nuclide. A detailed list of precautions in handling or storing radioactive organic compounds is included.

The fourth and most recent booklet, Standards of Activ. ity, discusses the types of standard available, their certification and use. The activity of a quantity of radioactive material is defined in accordance with the 1962 report of the National Commission on Radiological Units and Measurements (ICRU) (NBS Handbook 86) as the number of nuclear disintegrations which occur in the quantity in unit time. The curie, $5.7 \times 10^{10}$ disintegrations per sec, is the special unit of activity, and activity can be quoted in curies or in its sub-multiples. Activity is not constant with time but decays at a rate determined by the radionuclides present.

Because of uncertainties in purity and half-life, the accuracy to which the activity can be calculated at a given time becomes worse the longer the period from the reference time. Standards of activity have therefore an ephemeral nature and care must be taken in the interpretation of the title 'standard'. The most satisfactory physical form for a standard of activity is a solution in a flame-sealed glass ampoule, but other forms are available. Standards of activity are principally used for the calibration of measuring instruments, and the booklet makes clear the precautions to be taken if full use is to be made of the high accuracy associated with absolutely standardized solutions. In the second half of the booklet the standards available from the Radiochemical Centre are discussed and a complete schedule (operative during 196566) of standardized solutions together with details of their guaranteed accuracy and delivery time is given. Each of the four booklets contains a list of references.

S. WeINTRoub

\section{SCIENCE ABSTRACTS}

$\mathrm{M}^{\mathrm{s}}$ EMBERS of the Documentation Research Project section of the American Institute of Physics have carried out a comprehensive survey of published physics literature by a detailed analysis of the contents of the 1961 issues of Physics Abstracts (Section $A$ of Science Abstracts). A report of the survey has recently been published*. A total of 20,287 abstracts covering 405 periodicals from 29 countries were scrutinized, and certain details coded and transfered into machine-readable form. The method of coding used is described and illustrated by a code sheet and sample abstract. The specific codes chosen for the country of origin, the periodical, the language and the subject fields, which formed the four major fields of enquiry, are included in an appendix to the report. Each field is dealt with in detail in a separate section of the report. The greater number of papers were devoted to nuclear physics and solid-state physics. About half the articles abstracted during 1961 had been published

* The Journal Literature of Physics: a Comprehensive Study based on Physics Abstracts (Science Abstracts, Section A), 1961 I88ues. By Stella Keenan and Pauline Atherton. Pp. 156. (New York: The American Insti-
tute of Physics, 1964.) during that year. This may be closely related to the fact that Physics Abstracts uses the author abstract when available. There were twice as many author abstracts as signed abstracts. Incorporated in the report, in addition to the numerous tables of data and illustrative charts, is a reprint of an article in the Journal of Chemical Documentation $(4,157$; July 1964), in which a description is given of an investigation of the time-lag of coverage by Physics Abstracts with respect to three particular periodicals. The time-lag refers to the time in months between the date of issuo of the periodical in which an article appeared and the date of appearance of its abstract in Physics Abstracts. The three periodicals were Physical Review Letters (an English language journal with no author abstracts), the Journal of Chemical Physics (an English language journal with author abstracts for articles but not for Letters to the Editor), and Zeitschrift für Physik (a foreign language journal with author abstracts in English or in a foreign language). The investigation showed that the average time-lag was similar for all three periodicals, about three to four months. Many factors contributed 